\title{
BAHÍA DE BRISTOL, OCÉANO PACÍFICO
}

Daniel González Dueñas*

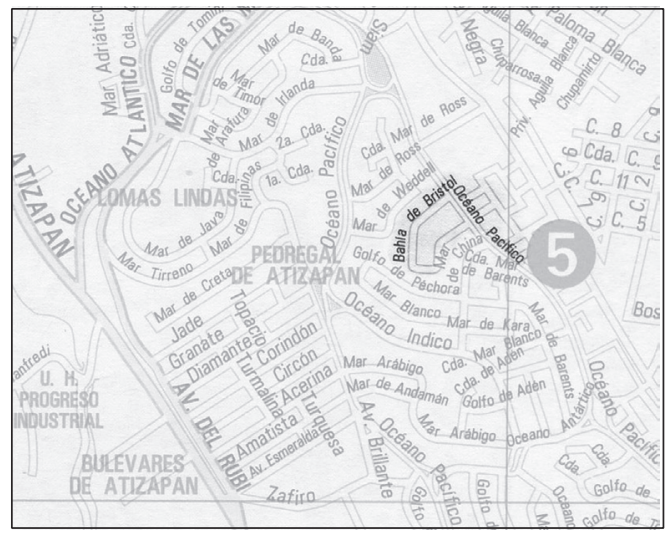

Esta cuarta versión del 'relato' es para Eurídice, antes de emprender su estrategia del sueño.

De los sueños hay que hablar como del amor o de los mitos, con una absoluta credulidad y no la del ingenuo sino la del que toma completamente en serio aquello de lo que habla (porque en el fondo nadie conoce el fondo de lo que habla). Entonces, tal vez comenzar hablando de los sueños en general, de cómo han sido siempre para mí una vida tanto o más real que la diurna. O tal vez comenzar hablando de Eurídice, que resultó ser mi compañera de travesías oníricas. Sin embargo, creo que lo mejor será relatar ese sueño: de pronto me encontraba en unas calles desconocidas, bastante confundido no sólo del sitio sino de cómo había ido a dar ahí. Lo increíble es esto: en vez de sucumbir al miedo -como es frecuente-y así desencadenar instintivamente el despertar, lo que hice fue detener

* Escritor. 
un taxi y pedir ayuda al taxista. Supongo que así actuaría alguien que sufriera un ataque de amnesia parcial en una calle de la vigilia: trata de conservar la calma, se adhiere a lo poco que sabe de sí y busca alguna clase de apoyo.

Sólo tres elementos circunstanciales recordaba con total nitidez: 1) poco antes yo había estado manejando una camioneta, una pick up color marrón, nueva; 2) el vehículo no me pertenecía: era propiedad de cierto amigo - no recordaba quién- y yo la tenía en préstamo para cumplir algún asunto -también incierto; 3) había estacionado la pick up en un lugar específico en las cercanías e ignoraba el porqué. Así pues, tenía recuerdos muy claros en cuanto a las circunstancias particulares, mas no en cuanto a sus orígenes o generalidades.

Otro punto curioso: en la medida en que me era fácil detallar esas imágenes en el pensamiento, me resultaba muy arduo articular palabras; me exasperaba estar balbuceando mientras intentaba decir al taxista que no podía recordar el nombre de la calle, aunque sí su aspecto. Yo había elegido tal sitio para estacionar la pick up precisamente porque sabría reconocerlo, y tenía muy clara la imagen de la esquina, mas no el nombre de la calle y ni siquiera del rumbo. El taxista me

106 escuchaba con la actitud de cualquiera de sus colegas experimentado en las excentricidades de la clientela. Incluso me ayudaba a buscar pistas del barrio, y hasta proponía dar vueltas en torno al sitio en donde me había recogido para ver si yo podía reconocer alguna zona.

Mientras avanzábamos en silencio, yo trataba de 'recomponerme', como se dice en las malas novelas; recuerdo incluso haber pensado que mis esfuerzos representaban lo que en inglés suena más ridículo aún: to pull myself together. Luchaba, pues, contra esa niebla que a veces nos aplasta en los sueños, desde luego ignorando que soñaba. De nada servía que describiera al taxista la calle y lo que había en ella: podría tratarse de cualquiera. Con un esfuerzo que me hacía sudar (un detalle curiosamente realista), intentaba establecer el nombre de la calle; sentía tenerlo 'en la punta de la lengua' y el no poder pronunciarlo me sumía en una angustia creciente. 
Otro recuerdo circunstancial me brotó entonces como un salvavidas en medio del naufragio: en el barrio en que había estacionado la pick up todas las calles tenían en el apelativo un elemento común, y casi estaba seguro de que eran ríos o pájaros o piedras preciosas, como suelen tener ciertas colonias mexicanas. Así, se me ocurrió hacer desfilar nombres para ejercitar la memoria y vencer a la niebla: Faisán, Granate, Amazonas, Topacio, Águila, Zafiro, Nilo, Diamante, Cisne, Turquesa, Amatista... Debo haber recitado docenas de posibles nombres -al principio con un esfuerzo inaudito- mientras dábamos vueltas y vueltas, yo en estado febril y el sabio taxista con una sonrisa comprensiva, divertido por el acertijo e incluso interesado en él: realmente quería ayudar. Jade, Támesis, Golondrina, Esmeralda...

Ahí comenzaba una serie de peripecias bastante oníricas -si pueden llamarse así, los soñadores me comprenderán-, pero lo curioso es que de pronto me desentendía de los pájaros y las piedras y me concentraba en los ríos (me parece que hasta llegué a considerar Río Rojo o Río Escondido), para después enumerar variantes como lagos, lagunas, mares o golfos. Recuerdo que hubo un largo momento consistente en una pura sucesión de palabras rescatadas de la amnesia (Hudson, Ebro, Grijalva, Temiagua, Mississippi, Pátzcuaro, Michigan, Ginebra, Constanza, Adriático, Báltico, Negro, Jónico...); ella me tranquilizaba y a la vez me confería más ánimos para buscar, para estar seguro de que esa calle no estaría lejos.

Desperté en algún momento de esa cascada de palabras. Una vez más atravesé esa misteriosísima transición, ese momento portentoso, esa escalofriante descolocación que es siempre la primera aunque se repita cada día: no sabes bien a bien quién eres, dónde estás, y vaya a saber si entonces, y sólo entonces, eres un quién y estás en un dónde, precisamente porque te hallas en la plena incertidumbre, en el absoluto extravío. Es ese pequeño nacimiento de cada jornada, ese instante supremo en que en verdad te recompones. Y en efecto vuelves a componerte: de todos los elementos del universo (el de la vigilia y el del sueño son uno solo) reconoces unos cuantos, siempre los mismos, los tomas y los armas, y ese rompecabezas eres tú y tu mundo. Aunque a 
veces no siempre son exactamente los mismos: uno se cuela por ahí, uno que ayer no estaba, un elemento supernumerario de tu conciencia y de tu identidad, quizás una clave, quizás una llamada...

En la confusa vuelta a la vigilia ignoraba si fui capaz de reconocer la calle o de agradecer la ayuda del generoso taxista. La cosa es que salté de la cama y busqué una hoja de papel en la que fui escribiendo los nombres de las calles que recordaba haber enumerado en el taxi. Luego me precipité a buscar una guía de la ciudad con mapas y una lista alfabética de calles. Mi proyecto era complejo: aunque me llevara horas, quería buscar uno a uno los nombres de mi lista en los diversos mapas, con objeto de ver si me resultaban conocidos sus alrededores.

En algunos casos había cientos del mismo nombre en muy diferentes colonias de la ciudad (más de seiscientos ríos, más de cien mares, casi cuarenta golfos, docenas de océanos...). Decidí buscar por piedras, y comencé con Esmeralda. Había diecisiete en muy distintos sitios, y fui una por una, buscando en los barrios correspondientes. Así di con un barrio lejanísimo llamado Lomas Lindas, en el noroeste de la ciudad, donde por supuesto no había estado jamás y del que incluso ignoraba su existencia; al ver los nombres que rodeaban a esta Esmeralda, quedé helado (¿cómo describir esa forma del reconocimiento que nada tiene que ver con los resortes de la vigilia?): ahí estaban casi todas las calles y todos los géneros que yo había recordado en el sueño.

Quizás esto en principio no sea tan extraño, porque en la nomenclatura de este barrio se mezclan golfos, océanos, mares, piedras, aves y además flores y frutas, y hasta próceres (aunque no ríos). Lo singular fue mi reacción: de pronto el dedo con que recorría el mapa se detuvo sobre una específica zona y supe, sin la menor duda, que la calle tan arduamente buscada en mi sueño era una bahía; de ahí mi obsesión con los ríos, golfos, océanos y mares. Tal vez debido a los restos del sueño reciente -es decir, a los restos de la percepción reciente-, la calle Bahía de Bristol brillaba en el mapa como si tuviera luz propia. Yo nunca había estado ahí, pero con una seguridad absoluta me dije: 
'Aquí estacioné la pick up'. Era la esquina de Bahía de Bristol con Océano Pacífico.

No sé si decir 'esquina' sea exacto porque, si se observa el mapa, se verá que muchas de las calles de esa curiosa zona son circulares (además, todas son rectas con excepción de las que tienen nomenclatura relacionada con el agua). Así, el pequeño óvalo Bahía de Bristol intersecta en dos puntos al gran óvalo Océano Pacífico. Éstas y otras cosas reconocía, trémulo, mientras pensaba, en completo deslumbramiento: "Por aquí andaba en el sueño y en el taxi, amnésico y balbuceante. Aquí estaba la pick up, así que todas esas vueltas que dimos en el taxi debieron ser acá abajo, donde se enredan los Golfos, o acá arriba, donde los Mares serpentean como ríos." Recordé que en un momento el taxista se había detenido a preguntar a una transeúnte, en un punto en que las calles ondulantes se volvían rectas. "Era por aquí o por acá", me dije señalando el plano, "donde las calles de piedras preciosas o de pájaros, en seca linealidad, colindan con el sinuoso laberinto acuático de Lomas Lindas. No me sorprende el extravío: sin un mapa, cualquier profano se pierde".

Más tarde pensé que no es inusual en los barrios mexicanos mezclar los géneros con tan alegre displicencia, y que buscando podría haber dado, tal vez, con otro caso similar. Sin embargo, sí era bastante extraño haber recordado en el sueño más de la mitad de los géneros de nombres que había en ese barrio. El posible curso de acción era inequívoco y hasta imperioso. Me vestí a toda prisa y tomé el primer taxi que pasó; el taxista nunca había ido a Lomas Lindas, naturalmente, y aquí fue de gran utilidad la guía de la ciudad y sus detallados mapas. No recordaba con precisión el rostro del taxista en el sueño, pero éste, el de la vigilia, era muy distinto, más joven, menos paciente, nada dispuesto a interesarse por la agitación de este cliente que era yo, capaz de hablar con soltura pero no de dominar la mano temblorosa con que sujetaba la guía, las listas en hojas de papel y una cámara fotográfica.

Aquí podría hallarse la semilla de un cuento fantástico, pero lo que realmente sucedió fue... nada. El desconocido diseñador urbano no era un mítico creador de laberintos: se había limitado a adaptarse a 
la curiosa topografía de la zona, entre lomas y cerros. Y en el sitio en que se cruzaban los óvalos Bristol y Pacífico (había ahí un pequeño parque) no estaba ninguna pick up, ni vi un solo elemento que me pareciera reconocible o significativo con referencia al sueño. No hubo un reconocimiento visual: lo singular era que en el sueño tenía muy clara la imagen de la intersección, mientras que en la vigilia lo único indudable era el nombre de las calles.

Tomé algunas fotos en esa intersección y luego pedí al taxista que diera varias vueltas por el barrio (que habría sido indescifrable sin un mapa), con los mismos resultados. Cuando regresábamos a la ciudad (el taxista me veía de tanto en tanto por el espejo retrovisor pero conservaba las distancias y evitaba cualquier pregunta sobre ese extraño viaje) pensé que tendría que ir una y otra vez a Lomas Lindas, a diversas horas, y esto me llevó a la idea completa: buscar por ahí un cuarto en alquiler, algún sitio desde donde pudiera observar ese cruce día y noche... Con sorna, me imaginé viviendo en esa colonia, ya conocido ahí como el loco de la ventana: llevaría un diario engrosado por los años en donde registraría cada vehículo que durante todo ese tiempo se hubiera estacionado en Bahía de Bristol y Océano Pacífico. ¿Alguna vez aparecería la pick up marrón, me vería a mí mismo bajar de ella, caminar por ahí en estado de extremo aturdimiento?

No, era más que absurdo (y el absurdo nada tiene que ver con la firmeza del mundo de la noche). Con nostalgia -y también con esa rabia que surge cuando saltan las obviedades más recónditas- me di cuenta de que no había estacionado la pick up en la vigilia. De nada me serviría observar (o vigilar, esa palabra que tanto se parece a vigilia) el cruce durante mil años. Si deseaba alguna respuesta, debía ir a ese punto del universo desde el otro lado.

En los días siguientes, desde luego, examiné todos los detalles posibles del sueño sin mayor deslumbramiento que el hermoso hecho de que, de este lado (curioso que llamemos así a la vigilia, si el sueño es también 'este lado'), la original Bahía de Bristol es también un canal y da a un golfo del Atlántico, no del Pacífico. No, no es ahí, en el puerto inglés de Gloucestershire, a orillas del Avon, entre Gales y 
Cornualles, en la desembocadura del río Severn, donde está la esquina. Era una forma verdaderamente genial de hacerme descartar la opción de viajar a Inglaterra. Esto era en efecto un acertijo y, más aún, un koan. Al estar desentrañando esas cosas me pareció escuchar la honda voz de una esfinge zen formulando el siguiente enigma: “¿Dónde la Bahía de Bristol toca al Océano Pacífico?” Yo había dado primero con la respuesta y luego con la pregunta sagrada, de otro modo.

Por supuesto, consideré la posibilidad de consultar los mapas de todas las ciudades de Latinoamérica, donde es más frecuente mezclar los géneros en las nomenclaturas urbanas. El primer paso en ese sentido fue consultar de nuevo la lista alfabética de calles en la guía. Sorprendido, descubrí que en esta ciudad, la más grande del mundo, había una sola calle llamada Bahía de Bristol. En esta megalópolis, pues, no hay más que un punto en que tal Bahía se cruce con Océano Pacífico. Aun si hubiera otro entrecruzamiento análogo en Caracas, Montevideo o Panamá, no sería el mío - ni equivaldría tampoco a la respuesta para el koan sagrado; en mi sueño me encontraba en la ciudad de México: la exacta confluencia me había sido claramente señalada.

Examiné todas las pistas, incluso el término pick up, que implica recoger, aprender, levantar, conocer, encontrar. ¿Recoger algo perdido, levantar algo postergado, encontrar algo oculto? Pero me interesó más aquel otro modismo inglés que en el sueño me había pasado por la cabeza y que en la reconsideración ya no me pareció tan ridículo: to pull myself together. ¿No es cierto que cada mañana nacemos de nueva cuenta, y que en ese instante de transición recordamos que no somos cosas monolíticas sino conjuntos, rompecabezas, combinatorias? Al entrar al sueño el caleidoscopio que somos se descompone una y otra vez hasta que volvemos a la vigilia. ¿Y qué estaba haciendo yo sino luchar, ahora doblemente, por juntar mis partes de ambos lados, recomponerme, completarme, ponerme entero? Ahí había una pieza que acaso completara y diera sentido a lo que antes no parecía un rompecabezas. (To pull together: ¿tomar la imagen de la intersección y reunirla con el nombre de las calles?) 
¿Por qué una pick up -me pregunté también- si nunca he tenido una, ni conozco a nadie que la haya tenido, y ni siquiera me gusta ese color? Acaso los soñadores comprenderán: camioneta marrón, ballena blanca... Los sueños hablan otro lenguaje (allá perdí el habla pero no las palabras, y acaso la demanda es no perder aquí el signo), y en vez de 'esquina' pueden estar hablando, tal vez, de la intersección, del centro. No faltará quien use otros eufemismos: la clave, la cifra, Dios...

No creo estar exagerando: me basta recordar el modo en que temblaban los mapas en mis manos durante la primera búsqueda. ¿Habré vivido en otra vida en Lomas Lindas? El aspecto de esa colonia hace suponer que no tiene más de veinte años de antigüedad. El vertiginoso crecimiento de esta monstruópolis devora montes y barrancas con igual voracidad, tal vez incluso ríos y bahías. No, no fue en 'otra' vida sino en ésta, la única, en donde está la respuesta.

A partir de entonces, antes de entrar al sueño acostumbro mirar las fotografías que tomé en Bahía de Bristol y Océano Pacífico. Y cada vez me doy cuenta de la necesidad de una cartografía: ¿encontraré allá otro mapa tan pormenorizado como el que fue aquí tan meritorio? Sin embargo, ¿en el mundo onírico un croquis será tan cambiante como el territorio que describe? Un mapa que registrara las sucesivas metamorfosis de una ciudad, ¿no sería en sí mismo otra ciudad? Y en el otro extremo de la escala: esta ciudad nuestra de todos los días, cualquier ciudad de lo que llamamos vigilia, ¿de qué inimaginable territorio será el mapa cambiante y exacto?

También resulta evidente la necesidad de un guía: ¿daré de nuevo con ese taxista o con otro Virgilio igualmente dispuesto? Me maravilla el hecho de que todo se da a través de correspondencias, como las llamaría Swedenborg; allá fallan las palabras, aquí los signos; allá el taxista era el guía sabio, aquí sólo era el indiferente testigo. Y hay otro tipo de correspondencias. Aquí he visto con tristeza las dos pick ups marrones que se han cruzado en mi camino desde la noche fulgurante: de nada serviría seguirlas, ni habría hallazgo incluso si una de ellas terminara por encaminarse hacia Lomas Lindas. Allá procuro encontrar a la única pick up que vale la pena, convocarla, invocarla, 
y me sucede deslizarme al sueño siguiendo una cascada de palabras, por ejemplo vigilia, vigilar, Virgilio...

P.D.: Semanas después de escrito lo anterior tuve un sueño que en honor al cine podría llamarse road dream, plagado de transcursos, retrocesos y rodeos en tranvías y autobuses, y más tarde a pie por calles de súbitos vientos furibundos que avanzaban en sentido contrario al mío y parecían querer detenerme. Al despertar me di cuenta, perplejo, de algo que en el sueño luchaba por imponerse a las peripecias y subtramas: me dirigía hacia Lomas Lindas. Acaso he emprendido el viaje en más de una ocasión sin recordarlo al despertar. Acaso algún día consiga vencer a ésos y otros vientos furibundos.

He decidido publicar todas estas páginas como si se tratara de un relato, una mera invención; acaso el texto mismo encuentre el territorio del que es un mapa tentaleante.

Nueva P.D.: Publiqué una primera versión del texto anterior en las páginas del suplemento sábado de unomásuno. Luego, corregido y aumentado, en el suplemento de Siempre! Un poco después de haber aparecido esta segunda versión, recibí una nota de Eurídice, una amiga generosa (juro que se llama así, ¿para qué mentir a estas alturas?).

Antes de citar el contenido de su nota, debo hablar de nuestra muy especial relación: de cuando en cuando uno de los dos sueña al otro y a la mañana siguiente nos llamamos para relatarnos los pormenores oníricos, algunas veces divertidos, otras con algún estremecimiento. Así nos enteramos de lo que hemos dicho y hecho en el otro lado, ahí donde el soñador lo comparte todo con el soñado pero debe relatarle todo una vez despierto.

Lo repito: ¿para qué tendría que mentir? Todo esto es absolutamente cierto. Si ella y yo nos soñamos, ¿por qué no postular que Eurídice estaba esa vez en Lomas Lindas? ¿Sería la transeúnte a la que el taxista le hizo una pregunta? ¿Sería incluso la amiga que me hizo el misterioso encargo inicial? (Y la amistad es aquí muy importante: un modismo inglés, to pick up with, significa trabar amistad.) Ingenuamente creemos que nuestro 'aquí', la vigilia, lo es todo. Pero ¿qué agitada y vertiginosa vida órfica se desarrolla allá, mitad secreta 
de este aquí y sin la cual nuestra vigilia se mantiene carente de un sentido integral?

La nota que Eurídice me envió decía lo siguiente: "Leyendo la revista en que publicaste tu cuento (y que llegó a mis manos por pura casualidad), quedé estupefacta. Déjame decirte que yo tengo una pick up color marrón. Nunca la has visto porque no la saco: es un monstruo que traga gasolina como un demonio, y manejarla es como meterse en una nave interplanetaria que no vuela pero en cambio (avestruz-tanque de guerra) ama lanzarse contra los vehículos para dejarles hermosas abolladuras color marrón que nadie le agradece. Te la puedo prestar para que lejos de los territorios oníricos llegues a las Lomas Lindas (y evites así los complejos derroteros en autobús y tranvía), atravieses el Río Rojo o Escondido, te encuentres con océanos, mares, piedras y una que otra fruta, y la estaciones en Bahía de Bristol y Océano Pacífico. En el texto dices que un amigo te hizo un cierto encargo y te prestó la camioneta para cumplirlo. Por eso te sugiero la siguiente estrategia: recorre la colonia mil veces hasta que la hayas memorizado palmo a palmo y seas capaz de situarte a pie desde cualquiera de sus puntos; luego llévate al demonio marrón, estaciónate en Bahía de Bristol y Océano Pacífico y duérmete ahí mismo, ante el volante. De ti depende lo demás, ya estando del otro lado... Si no vuelvo a saber de ti, al menos ya sé dónde recoger la camioneta (dicho en el buen inglés que te ha servido para saberte incompleto: to pick up the pick up). Descuida: tengo un duplicado de las llaves."

Otra P.D.: He publicado una nueva versión de este 'relato' en la revista El Espejo de Urania, con mayores correcciones; y es que cada vez que leo una versión anterior recuerdo más detalles, encuentro intersticios antes inadvertidos, zonas por las que había pasado de largo, nuevas claves, incluso sueños incubados dentro de otros sueños. Por un lado siento que antes de emprender la expedición debería haber terminado un texto que explicara sus orígenes (si eso es 'explicar') y numerara sus claves de la forma menos precaria posible. Pero por 
otro lado me doy cuenta de que eso es tal vez un pretexto, y que la principal razón de que haya demorado el viaje es el miedo.

Una noche, hace muy poco, desperté con un inconfundible sabor de reconocimiento. Había tenido un sueño que sólo puedo calificar como 'recursivo', a la manera de las muñecas rusas, y que procedo a describir (pero los sueños no se describen, apenas se asombran, es decir que apenas se registra en palabras una leve sombra de lo que fueron). Iba caminando cada vez con mayor dificultad, exhausto $-\mathrm{y}$ ya no es difícil adivinar hacia dónde me dirigía-, y de pronto vi una puerta que me resultó familiar. Era la casa de Eurídice. Abrí y entré; yo conocía perfectamente el lugar aunque nunca había estado ahí: se hallaba deshabitado. Fui directamente a una especie de terraza con poltronas y me tendí en una de ellas para dormir un poco. (Dormir dentro del sueño, qué viejo resorte, qué pista suelta.)

Ahora viene lo fascinante: dentro del sueño me quedo dormido y sueño a una mujer a la que no conozco; sin embargo, de alguna forma 'sé' que vive en una casa cercana a la mía, ambas en una especie de 'cerrada', como llaman en México a calles con una sola vía de ingreso. Conversamos un momento; ella parece tener prisa, echa el cerrojo desde afuera y pega con cinta adhesiva una hoja de papel en la que está escrito un recado dirigido a un tal Luis. La mujer se aleja y yo echo un vistazo a la nota; dice más o menos esto: "Nos hemos adelantado en varios coches. Éste es un plano para que nos alcances." Luego hay una serie de dibujos e indicaciones para llegar a ese sitio: 'toma tal y cual carretera', etcétera.

Entonces despierto en la poltrona de la casa de Eurídice; es decir, retorno al primer sueño sin saber que sigo soñando, y recuerdo el sueño que he tenido. Aún más: veo con cierta claridad ese mapa que la mujer había pegado en la puerta de su casa. Los mapas y las indicaciones se suceden en mis sueños, pero éste es el más asombroso, puesto que se mueve, cambia, late como si estuviera vivo. No tiene nada que ver con aquel otro mapa que ya sé de memoria, pero ahí, en la poltrona, incapaz de moverme, reconozco algo en la forma en que las líneas cambian y ondulan, y me digo: 'Bristol'. En ese instante desperté a 
la vigilia, si esto es realmente una vigilia. Resulta más que evidente que esa mujer, sus acompañantes y el misterioso Luis iban también a Lomas Lindas. El saber que otros soñadores se dirigen al mismo sitio, a partir de distintas claves y señuelos, no hace sino apresurar mi plan. Mañana, hoy mismo iniciaré la expedición. 